\title{
The Impact of Trust on the Willingness of Co-Tenancy Behavior: Evidence from China
}

Xiaofeng Yu*
Xiaoxue Zhang*

School of Media and Communication, Shenzhen University, Shenzhen, People's Republic of China

*These authors contributed equally to this work

\author{
This article was published in the following Dove Press journal: \\ Psychology Research and Behavior Management
}

\begin{abstract}
Introduction: Nowadays, more and more people choose to rent houses in first-tier cities together with other people, which can alleviate certain economic pressure. Therefore cotenancy has become an important field of academic research in recent years and a number of previous studies have discussed the phenomenon. However, fewer studies explore the influence of different variables on the willingness of co-tenancy behavior through quantitative methods.
\end{abstract}

Methods: This study conceptualizes and implements concepts such as trust, positive emotion, relationship strength, satisfaction, income, duration of co-tenancy required and the willingness of co-tenancy behavior(WOCB). We designed and collected a questionnaire and finally a questionnaire survey of users $(n=525)$ was conducted, and a basic description and comparison of research objects' willingness of co-tenancy behavior were made in terms of trust, and positive emotion, relationship strength and monthly income also affect the willingness of co-tenancy behavior.

Results: The trust effects have a positive impact on the WOCB, Trust effect will affect Relationship Strength and Positive Emotion, and will further affect the WOCB. However, this influence is negative when people are in high Monthly Income and negative when people are in low Monthly Income.

Discussion: Trust, relationship strength and positive emotion are key factors for people to rent houses with others. That is to say, the intensity of people's willingness to rent houses with others depends on the degree of trust in others, the relationship strength and positive emotion. When the post-90s drifters in Shenzhen do not believe others, they will tend to live alone rather than the new model of co-tenancy. We also suspect that a person with negative emotion far greater than positive emotion prefers to live alone, rather than living in the same place with his roommates. It provided certain group implications for their willingness of cotenancy behavior.

Keywords: trust, positive emotion, relationship strength, the willingness of co-tenancy behavior

\section{Introduction}

Shenzhen is located in the south of China. As a fast-growing emerging first-tier city, Shenzhen has been hailed as an "internationally renowned immigrant city" in decades. At the same time, its rapid rise in economic status makes it one of the central cities in Guangdong-Hong Kong-Macao Greater Bay Area (GBA). As the backbone of urban development, more and more post-90s Shenzhen drifters have come to new cities. In this study, our research object is the post-90s drifter in Shenzhen. We define the drifters in Shenzhen in this article as the younger generation who come to live and work in Shenzhen from other places but do not have 
Shenzhen "hukou" (a kind of registered permanent residence) or housing. And the post-90s drifters in Shenzhen refer to people born after 1990, who work and live in Shenzhen with their own abilities and academic qualifications but have no Shenzhen "hukou" or housing. They have higher education, stable work, and strong adaptability. There is a small social distance between the development mode and space of their life and that of the mainstream society, and they have certain ability and way to enter the mainstream society as immigrants.

Housing has always been an important consideration for people, which is closely related to people's quality of life, property investment and potential future economic security. ${ }^{1}$ And the most important consideration for the post-90s drifters in Shenzhen to solve is stable houses for them. It is without doubt that renting houses with friends, colleagues or strangers becomes a new living mode that is chosen by first-tier cities and new first-tier cities in the post-90s generation nowadays. As a form of living together, co-tenancy appeared in different countries at the beginning of the 20th century. As a matter of fact, until the end of the $1990 \mathrm{~s}$, only $1 \%$ to $2 \%$ of the people in their 20 s shared houses. ${ }^{2}$ With the development of cities and lives, the post-90s generation in newly developed cities has gradually become a main body of the shared group. Regardless of income sharing, it is becoming a new main form, which provides a new possibility to provide housing for urban singles of all ages. ${ }^{3}$ Young people's choice of sharing is usually regarded as a short-term transitional arrangement, that is to say, shared housing is often considered as a stage of many possible "transitional" or "intermediate" living arrangements, which are not only limited by economic factors but also a young people's choice, which is of great significance to them. ${ }^{4}$ In fact, for many young people who have just stepped into the society from school, they are often experiencing a brandnew life stage, and the function of shared housing is like a transitional student dormitory. ${ }^{5}$ For example, the function of joint houses is similar to that of a college dormitory. Students living in dormitory often regard dormitory as a place where they can rest in a fixed time, and it includes the function of public washroom.

In this paper, the object of study is the post-90s drifters in Shenzhen. The core question that brings me to think about is what factors are closely related to the Willingness of Co-tenancy Behavior rent in the group?

Before setting the variables of the Willingness of Cotenancy Behavior in the post-90s generation in Shenzhen, we interviewed 20 post-90s drifters in Shenzhen in March 2020. Because it is very important to do qualitative research before quantitative research and find out which variables have an impact on them. The results of qualitative investigation are helpful to develop and perfect the hypothesis about how trust works and can be used to generate questions for structured questionnaires and the Quantitative s investigation is valuable because it allows for larger-scale investigation and data generation. ${ }^{6}$ Therefore, based on the results of literature reading, indepth interviews and collecting and sorting out these interview data, we summarized the variables such as trust, income, positive emotion, relationship strength, satisfaction and duration of co-tenancy required (ie, How long do they need or want to share the rent, DOC).

\section{Literature Review}

The theoretical framework in the study is primarily the theories of trust, positive emotion, strength relationship and satisfaction which further explores the Willingness of Co-tenancy Behavior (WOCB).

\section{Trust and the Willingness of Co-Tenancy Behavior (WOCB)}

Trust plays a vital role in the process of interpersonal communication whether online or offline. At present, although there are many researches on the factor of trust in different fields, and the research on trust is becoming more and more popular in academic research fields, the concept of trust is often regarded as a vague and difficult concept to define. Even in the concept of trust, there is a conceptual distinction between general trust and trust between people. For example, Larzxelere and Huston (1980) define the former as a person's belief about the character of people in the aggregate and the latter as 'a belief in the integrity of another individual'. 7 The trust between people is usually considered as the behavior that needs to be adapted to a specific environment. Cummings and Bromiley (1996) defined interpersonal trust as the goodwill efforts of another individual or group to act according to the promises, to maintain integrity and honesty in the negotiations before these promises, and not to make excessive use of others' goodwill even if there is an opportunity. ${ }^{8}$ Balliet et al (2013) define trust as an expectation of cooperation. ${ }^{9}$ In our daily life, people often decide whether to trust or cooperate with an unfamiliar person according to their facial expressions or hearsay or 
one-time impression of each others Behavior. ${ }^{10}$ Trust is reflected in such a situation: an important goal and a highly uncertain result, when relying on another person, it is expected to increase the possibility of an ideal result. ${ }^{11}$ The BDT (base, domain and target) framework describes adolescents' interpersonal trust as multidimensional, through BDT model, trust is regarded as an expression based on trust, emotional respect and city. ${ }^{12}$ McAllister (1995) believes that interpersonal trust has a cognitive and emotional foundation: the cognitive foundation is based on the credibility and reliability of individuals to their contacts; Emotion is based on interpersonal interaction, mutual care and care. ${ }^{13}$ Goudge et al (2005) learned from previous studies to investigate how trust can be measured and explored how to measure trust in different disciplines under different backgrounds and provided researchers with different methods for different backgrounds. ${ }^{6}$

In reading and sorting out the literature, we find that only a few papers are mainly aimed at exploring the significance of trust in certain specific environments or specific interviewees, and these papers mainly use qualitative data collection and analysis methods. Most articles mainly use structured survey tools to measure trust, which can be divided into two situations, one is to consider the statistical correlation between trust and result variables, and the other is to study the differences between different levels of trust in different environments. Most researches on trust for certain groups or environment mainly come to conclusions in a purely qualitative form through semistructured interviews or participatory observation or focus interviews. ${ }^{16-18}$ In the study of trust as an influencing factor, Zhu et al $(2020)^{20}$ studied the trust between closely related individuals (inner groups) and non-closely related individuals (outer groups). After reading these papers, we think that the proper definition of trust is highly dependent on the specific issues to be studied. Trust is often found to support cooperation that enables a series of actions to be realized. ${ }^{8}$ In some cases, the judgment based on trust is regarded as a calculated decision, while in other cases, it is regarded as an intuitive or emotional response. ${ }^{21}$ Different research fields have different definitions of Behavioral willingness, and the research on Behavioral willingness can be traced back to the theoretical model of consumer decision-making. Generally speaking, when people make certain decisions, this mechanism will be triggered, and the core mechanisms are belief, attitude and intention. This can be well proved in the Theory of Rational Action and Davis's Technology Acceptance Model $^{22}$ These are common theories used in the study of Behavioral intention. In the field of Consumption, consumers' behavioral willingness will be defined as consumers' intention and decision about commodity purchase Behavior. From a sociological point of view, the Tripartite Attitude Model is also an important model for studying Behavioral willingness. There are three important factors in the model: cognition, emotion and conation. ${ }^{23}$ Cognition is people's thoughts and attitudes towards objects, including concrete thoughts of believing in certain facts. Emotion is the fluctuation of feeling, mood or emotion that can be described by language or measured by psychological reaction, intention is the willingness to act. Among the guests as well as hosts, the most important thing is to encourage trustworthiness that can help to mitigate the associated risks for peer-to-peer sharedhome. $^{24}$

In this study, based on the researches' definition of trust and the specific context, we defined trust as the post-90's generation of drifter in Shenzhen can generate confidence in the reliability or integrity of their co-tenants and confidence in the best interests of their co-tenants. At the same time, the Willingness of Co-tenancy Behavior (WOCB) is defined as the Behavioral intention and decision-making to rent houses together. Therefore, the first hypothesis of this study is:

H1: the trust effects have a positive impact on the Willingness of Co-tenancy Behavior (WOCB), that is the higher the degree of trust between the post-90's generation of drifter in Shenzhen, the stronger the Willingness of Cotenancy Behavior(WOCB).

\section{Relationship Strength (RS) and WOCB}

As an important field, Relationship Strength has always been concerned by many scholars. ${ }^{25,26}$ The professionalism of information dissemination, the professionalism of the receiver and Relationship Strength between them will significantly affect the influence of word-of-mouth on the decision-making of the receiver's purchase Behavior. ${ }^{25}$ Smith (2002) found through empirical research that under the Internet environment, the professionalism of word-of-mouth recommenders and Relationship Strength between recipients and recommenders have an impact on consumers' purchasing Behavior decisions. ${ }^{26}$ Wang and $\mathrm{Li}$ (2007) found that perceived professionalism and relationship strength have a significant positive impact on 
purchasing decisions through the mediation of trust, and they think that relationship strength refers to the close relationship between the receiver and the information disseminator, and the relationship strength can be divided into strong relationship and weak relationship. ${ }^{27} \mathrm{Xu}$ (2007) found through empirical research that the relationship between consumers and information communicators, consumers' dependence on the online word-of-mouth communication platform, consumers' perception of the usefulness of websites, perceived risks and trust tendencies all have a positive and significant impact on consumers' online word-of-mouth credibility and communication effect. ${ }^{28}$ Bi (2010) explored the relationship among several variables, such as trust, perceived risk, disseminator's professionalism, relationship strength, product involvement and brand impression, and among them, trust and perceived risk are the mediator variables of negative online word-ofmouth affecting consumers' Behavior intention. ${ }^{29}$ Cheng (2011) take the virtual community as the platform and take the characteristics of word-of-mouth sender, website and word-of-mouth receiver as independent variables, trust as mediator variable and online word-of-mouth influence as dependent variable, and then verified its model by SPSS 17.0 and Visual plus 1.04, it was concluded that the professionalism and homogeneity of word-of-mouth sender, Relationship Strength between word-of-mouth sender and receiver, and the credibility of website all significantly and positively affected the impact of online word-ofmouth on consumer Behavior. ${ }^{30}$ Based on this, we define Relationship Strength as whether the relationship between the partners is close or not in the lives of co-tenancy.

H2: Trust will affect Relationship Strength, and will further affect the Willingness of Co-tenancy Behavior. That is to say, the degree of trust among the post-90s who tend to share houses with others in Shenzhen will affect Relationship Strength, and then will affect people's willingness to co-tenant.

\section{Mediator Variables: Positive Emotion (PE) and WOCB}

Emotion serves a wide range of important social functions, including the regulation of interpersonal relationships, positive emotions, although understudied, are particularly critical to the formation and maintenance of social bonds. ${ }^{31}$ Dunn et al (2005) studied the relationship among positive emotion, gratitude and trust. ${ }^{32}$ Qiu et al $(2008)^{33}$ revised the PANAS(Positive Emotion and
Negative Emotion Scale) compiled ${ }^{34}$, based on the theory of two-dimensional structure of emotion, using the method of expert evaluation and questionnaire survey, during the research, 218 valid questionnaires were collected, and the items were analyzed and screened by exploratory factors, and 33 words describing positive and negative emotions were obtained at the same time, descriptors (17) describing positive emotional experience include active, alert, dedicated, firm, enthusiastic, excited, encouraged, interested, proud, powerful, cheerful, energetic, delighted, surprised, cheerful, happy and grateful, descriptors (16) describing negative emotional experience include fear, panic, tension, jittery, irritability, hostility, guilt, shame, sadness, distress, fear, contempt, anger, frustration, anger and anxiety. Generally, after experiencing positive emotions, individuals are more likely to trust others. ${ }^{35}$ The structure of individual emotional experience can be described by two independent dimensions: positive emotion and negative emotion. ${ }^{34}$ Wang et al (2016) explore the relationship among emotional intelligence, self-leadership, self-efficacy, stress coping style and positive emotion by a questionnaire survey of 575 college students. ${ }^{36}$ Bastian et al think that the experience of positive emotion is closely linked to subjective well-being.

In this study, based on the positive emotion of PANAS we define positive emotion as the pleasure level of the post-90's drifters in co-tenancy life in Shenzhen, including passion, high energy, mental alertness, certainty, and so on. Based on this, we put forward the following assumptions:

H3: Trust will affect people's positive emotions, and will further affect the Willingness of Co-tenancy Behavior. That is to say, the degree of trust among the post-90s who tend to share houses with others in Shenzhen will affect people's positive emotions, and then will affect people's willingness to co-tenant.

\section{Moderator Variables: Monthly Income (MI), Duration of Co-Tenancy (DOC), Satisfaction and WOCB}

Monthly Income (MI) is an important reference factor in the post-90s drifters in Shenzhen. In the interview process, most of the post-90's drifters in Shenzhen said that they were green hands in the workplace. Although they have higher wages than second-and third-tier cities, if they want to save a sum of money in a place like Shenzhen, the expenses of food, clothing, housing and transportation will have to be reduced accordingly. In addition, in the process 
of combing and integrating the literature, we find that monthly income was discussed by different scholars as a key factor. Different levels of income have different effects on people's happiness. ${ }^{37} \mathrm{Yu}$ (2020) thinks that housing is the main expenditure of residents' income in China, which has a significant impact on people's wellbeing. ${ }^{38}$ In the study, gender, age, physical health, education et al are taken as control variables. It is without doubt that income is an important reference factor among different variables such as happiness, housing and life satisfaction.

Based on this, income as a variable in this paper refers to the subjective judgment in a certain period of time from the psychological level, with different degrees expressed by very low, low, medium, high and very high, respectively, in the questionnaire.

During the in-depth interview, we find that most of the post-90s drifters in Shenzhen rent houses with others for a short time, including those who rented for less than three months, and those who shared the rent for one year or even longer; therefore, we consider the DOC factor as an important factor. We think that whether some post-90s drifters in Shenzhen took co-tenancy as a forced choice for transit accommodation, that is, the length of time would affect the willingness of co-tenancy Behavior. Ling et al (2004) think that sharing economy is a typical representationtaking online short rent as an example, and think that short rent is a short-term accommodation service between hotel accommodation and individual housing rental. ${ }^{39}$ Long-term rental apartment is a rental apartment in which the apartment operators transform and upgrade the houses collected from the stock market, and provide diversified public space allocation and standardized property services (such as paying utilities, cleaning regularly, holding various sharing activities, etc.) to attract market people to stay (the lease period is generally several months or more). ${ }^{40}$

Based on the different time demands of the post-90s drifters in Shenzhen. We take the required co-tenancy time as the moderator variable in the model to explore whether it can adjust the relationship between trust and the Willingness of Co-tenancy Behavior (WOCB). Therefore, we define the duration of co-tenancy (DOC) as the length of co-tenancy time required for the post-90s drifters in Shenzhen. In the questionnaire, different lengths of time are expressed as very short, short, medium, long and very long, respectively.
There are rich researches on satisfaction at home and abroad, and the research on satisfaction has become mature. The United States, Sweden and other developed countries have established national satisfaction indicators. And in China, the related achievements are gradually improving and fruitful. Satisfaction is often used to describe consumers' feelings or attitudes towards various factors affecting their situation, which is a psychological state. ${ }^{41}$ And satisfaction is a comprehensive evaluation of the overall situation of housing made by households after using residential products and feeling related services. $^{42}$ Actually the Willingness of Co-tenancy Behavior (WOCB) is also a kind of buying and selling consumer Behavior. Liu et al (2013) established an evaluation model of tenants' comprehensive satisfaction and calculated tenants' satisfaction through quantitative methods. ${ }^{43}$

Based on this, we define satisfaction as the feeling of the post-90s drifters in Shenzhen in their co-tenancy life and the feeling is explicit or implicit or necessary needs or expectations of the co-tenancy life have been met. So according to the income, DOC and satisfaction, we put forward the following assumptions:

H4: Trust effect will affect Relationship Strength and Positive Emotion, and will further affect the Willingness of Co-tenancy Behavior. However, this influence is negative when people are in high Monthly Income (MI) and negative when people are in low Monthly Income(MI).

H5: Trust effect will affect Relationship Strength and Positive Emotion, and will further affect the Willingness of Co-tenancy Behavior. However, this influence is positive when the duration of co-tenancy required is shorter, and negative when the duration is shorter.

H6: Trust effect will affect Relationship Strength. However, the influence is positive when there is higher satisfaction and negative when there is less satisfaction.

We now construct a research theoretical model of "Trust $\rightarrow$ the Willingness of Co-tenancy Behavior(WOCB)": trust is taken as an independent variable and WOCB as a dependent variable, control variables are gender, education, age, occupation, and marital status, mediator variables are Positive Emotion/Emotion (PE) and Relationship Strength(RS); Moderator variables are income, DOC and satisfaction. And through the empirical analysis of this model to explore the impact of trust on the WOCB. The research model is the following (Figure 1) 


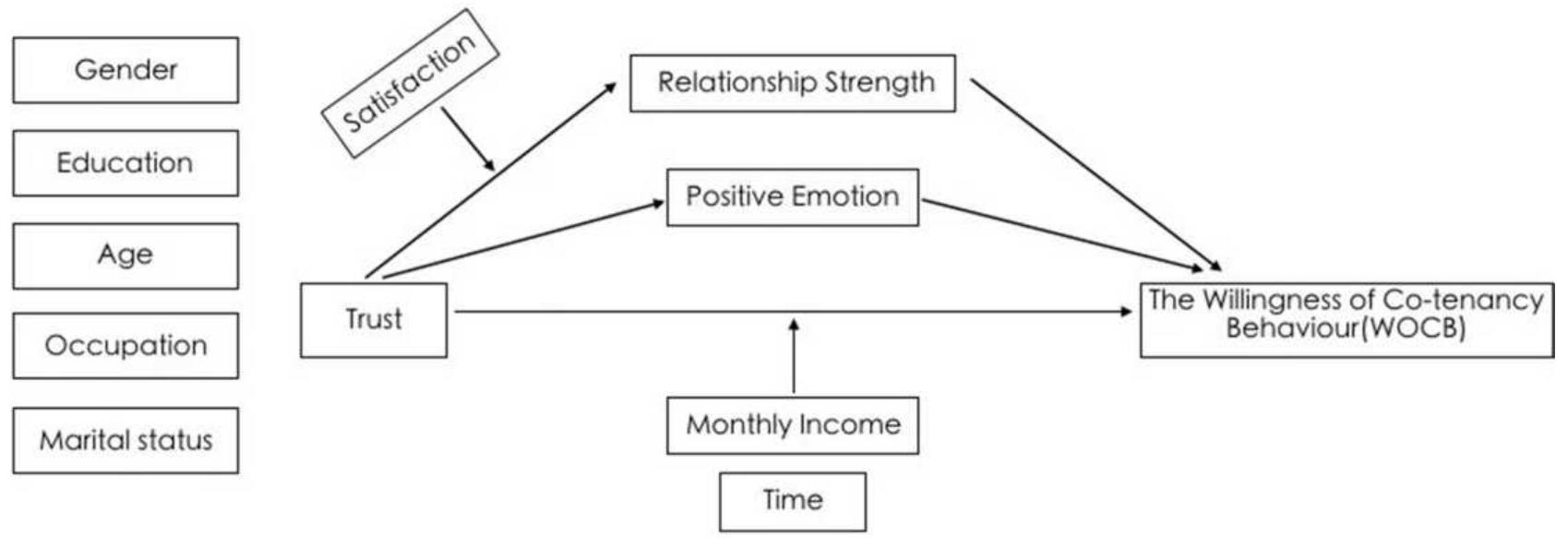

Figure I Research theoretical model.

\section{Research Method Design of Questionnaire}

Questionnaire is the main research method in the study. Based on Latent variables: Trust, Positive Emotion (PE), Relationship Strength (RS), income, DOC and satisfaction, we establish the corresponding scale in this study (Table 1: Variables measurement scale).

The main part of this questionnaire is Likert five-level scale. There are 4-7 questions statements about the measurement content on the scale, and each group of questions statements is measured by scoring, in which the scoring items are mainly divided into five items: $1-5$ points, respectively, indicate very disagreement opinions, relatively disagreement, general agreement, relatively agreement and very agreement. And the questionnaire of this study mainly includes three parts, the first part includes "Are you a post-90s generation?", "Do you think you are a drifter in Shenzhen?" And "Have you ever rented a house with others? " The three items are screened to judge if they belong to this research object, if three items are all "Yes", they will enter the second part or they will finish the questionnaire. The second part is the basic information including gender, the level of education, specific age, marital status, occupation and monthly income. The third part is the main part of the questionnaire, A total of 33 items are designed to measure the latent variables such as trust, Relationship Strength, satisfaction, positive emotion, income, DOC and the Willingness of Co-tenancy Behavior (WOCB).

In the process of questionnaire design, based on the interview contents of 20 interviewers and the opinions of people, the questionnaire is improved continuously to express the practical significance of each item clearly, simply and concisely so that the respondents can complete the questionnaire efficiently in the process of filling out the questionnaire. Before the formal distribution of questionnaires, we distribute 50 test questionnaires for pre-test through Wenjuanxing, a professional platform in China to make questionnaires. After cleaning the questionnaire data, 5 of them were invalid and 45 were valid questionnaires. And then we imported these data to SPSS25.0, it is shown that the reliability and validity tests were within the ideal range. Finally, the questionnaire of this study is finalized.

\section{Questionnaire Collection}

We distribute the questionnaire through the mobile terminal and PC terminal using Wenjuanxing at the same time in May 2020, and the respondents can fill out the questionnaire online. And we will give them one yuan as a reward to motivate them to complete the questionnaire. In order to reduce the error caused by non-random sampling, we also carried out the following operations in the Wenjuanxing platform: for instance: setting the questionnaire to be completed within a certain time, asking them to complete all the items, otherwise they will not be able to submit the page, Adding a reminder, that is, when the process exceeds 20 minutes, the system will automatically shut down and consider it invalid. At last, we set a confusing item on the scale of trust. If there are obvious differences between them, they will be regarded as invalid questionnaires. A total of 640 questionnaires were collected. The targeted questionnaire was 598, 42 respondents did not meet the requirement. In addition, by screening and eliminating the collected questionnaires and clearing 
Table I Variables Measurement Scale

\begin{tabular}{|c|c|c|c|}
\hline Variables & Code & Items & Sources of Scale \\
\hline Trust & $\begin{array}{l}\text { Al } \\
\text { A2 } \\
\text { A3 } \\
\text { A4 } \\
\text { A5 }\end{array}$ & $\begin{array}{l}\text { I usually have faith in roommates. } \\
\text { I tend to rely on my roommates. } \\
\text { I think human nature can be reliant. } \\
\text { I usually trust others unless they give me a reason to distrust } \\
\text { them. } \\
\text { I think my roommates are generally reliable. }\end{array}$ & $\begin{array}{l}\quad 44,45 \\
\text { Ridings et al } \\
\text { This research }\end{array}$ \\
\hline $\begin{array}{l}\text { the Willingness of Co-tenancy Behavior } \\
\text { (WOCB) }\end{array}$ & $\begin{array}{l}\text { BI } \\
\text { B2 } \\
\text { B3 } \\
\text { B4 } \\
\text { B5 } \\
\text { B6 } \\
\text { B7 }\end{array}$ & $\begin{array}{l}\text { I think it is convenient and feasible to choose co-tenancy. } \\
\text { Compared with living alone, I prefer to rent a houses with others. } \\
\text { Even if my funds permit, I prefer to continue co-tenancy. } \\
\text { I am willing to rent a houses with others. } \\
\text { I like the feeling of co-tenancy. } \\
\text { I am willing to recommend the co-tenancy lifestyle to others. } \\
\text { If my friend is considering co-tenancy, I will tell them the co- } \\
\text { tenancy information. }\end{array}$ & This research ${ }^{46,48}$ \\
\hline $\begin{array}{l}\text { Positive Emotion } \\
\text { (PE) }\end{array}$ & $\begin{array}{l}\mathrm{Cl} \\
\mathrm{C} 2 \\
\mathrm{C} 3 \\
\mathrm{C} 4 \\
\mathrm{C} 5 \\
\mathrm{C} 6 \\
\mathrm{C} 7 \\
\mathrm{C} 8 \\
\mathrm{C} \\
\mathrm{Cl}\end{array}$ & $\begin{array}{l}\text { I have endless energy. } \\
\text { I feel that I can do anything I want. } \\
\text { I like myself. } \\
\text { My thoughts are clear and creative. } \\
\text { I feel that people love me and trust me. } \\
\text { I feel close to the people around me. } \\
\text { My life is moving in the direction I want. } \\
\text { I often smile and laugh } \\
\text { I can handle anything that happens. } \\
\text { My future is bright. }\end{array}$ & $\begin{array}{l}\text { Watson et al }(1988) \\
\text { Kammann\&Flett }{ }^{49} \text { This } \\
\text { research }\end{array}$ \\
\hline Satisfaction & $\begin{array}{l}\text { DI } \\
\text { D2 } \\
\text { D3 } \\
\text { D4 } \\
\text { D5 }\end{array}$ & $\begin{array}{l}\text { My co-tenancy life is close to the ideal state in many aspects. } \\
\text { My co-tenancy living conditions are very superior. } \\
\text { I am very satisfied with my co-tenancy life. } \\
\text { I have got what I want most in my life. } \\
\text { If I can choose my life again, I will not make any changes. }\end{array}$ & [SWLS] This research ${ }^{50}$ \\
\hline Relationship Strength & $\begin{array}{l}\text { EI } \\
\text { E2 } \\
\text { E3 } \\
\text { E4 }\end{array}$ & $\begin{array}{l}\text { I have similarities with my roommates. } \\
\text { I am familiar with my roommates. } \\
\text { When roommates are in trouble, I will try my best to help them } \\
\text { out. } \\
\text { I will discuss personal topics with my roommates. } \\
\text { I am willing to make friends with my roommates. }\end{array}$ & This research ${ }^{51,52}$ \\
\hline
\end{tabular}

the data, there are 525 valid questionnaires, and the effective rate reaches $82.03 \%$. In this study, our final sample size is 525 cases, which is enough. One of the most fundamental issues in PLS-SEM is that of minimum sample size estimation, where the "10-times rule" method has been a favorite ${ }^{53}$ because of the simplicity of its application, it is based on the rule that the sample size should be greater than 10 times the maximum number of inner or outer model links pointing at any latent variable in the model. ${ }^{54}$ We judged it according to 10 times method. We conduct prospective approaches before data collection and analysis. The number of items is 32, and 525 is more than 10 times. So the sample is adequate to analyze data.

\section{Survey Sample}

We make a descriptive statistical analysis of gender, age, education level, marital status, monthly income and cotenancy experience. The results are as follows: more men $(66.48 \%)$ choose to rent with others than women $(33.52 \%)$. The education level of the post-90's co-tenancy drifters in Shenzhen is mainly young generation who are from technical secondary school and university, accounting for $80.76 \%$. 
And the age of the group is mainly concentrated in 21 to 26 years old, accounting for $84.95 \%$. And people over 26 will not tend to choose to rent a house with others. And most of them were unmarried $(81.14 \%)$. Most of them are company employees (which are related to many companies in Shenzhen) and freelancers, accounting for $70.29 \%$. There are very few civil servants in Shenzhen to choose to rent houses with others, accounting for only $2.29 \%$. The main reason is that civil servants in Shenzhen are well paid and they have a high quality of life. In addition, the monthly income is mainly 3000-9000 yuan (74.48\%). They often have many co-tenancy experiences (about $71.62 \%$ ) in the group, and most people have had the experience of renting houses by themselves $(88 \%)$.

\section{Data Analysis and Hypothesis Testing}

In this study, the data analysis mainly includes two parts. The first part is to use SPSS 25.0 to analyze the reliability and validity of the questionnaire, Correlation and regression analysis and so forth. And then we use Amos 24.0 to analyze the path to verify the hypothetical model constantly.

\section{Reliability and Validity}

Reliability refers to reliability, stability and consistency, which mainly refers to the degree of the same result when the same object is repeatedly measured by the same method and means. ${ }^{55}$ In this study, the reliability of the questionnaire was analyzed by SPSS 25.0. The Cronbach's Alpha is most commonly used to test the consistency of the questionnaire measurement items in this study. The higher the reliability coefficient, the more consistent the results of this questionnaire, and the higher the reliability and stability. The reliability test results of this research questionnaire are shown in the following part (See Table 2).

According to the table, the overall Cronbach's Alpha is 0.971 , which is greater than 0.8. It is an ideal range of reliability value, indicating high reliability. The Cronbach's Alpha of trust, Relationship Strength, positive emotion/Emotion, satisfaction and the Willingness of Cotenancy Behavior(WOCB) are all above 0.8, indicating high reliability, so the 7 variables in the questionnaire all have passed the reliability test. However, income and DOC are continuous variables of non-scale questions, which do not need to be tested for reliability and validity.

Validity analysis of the questionnaire refers to whether the results measured by the questionnaire are consistent
Table 2 Sample Reliability Analysis

\begin{tabular}{|l|c|c|}
\hline Variable & $\begin{array}{c}\text { Cronbach's } \\
\text { Alpha }\end{array}$ & $\begin{array}{c}\text { Number } \\
\text { of Items }\end{array}$ \\
\hline Trust & 0.895 & 5 \\
\hline Relationship Strength (RS) & 0.881 & 5 \\
\hline $\begin{array}{l}\text { The Willingness of Co-tenancy } \\
\text { Behavior (WOCB) }\end{array}$ & 0.933 & 7 \\
\hline Satisfaction & 0.881 & 5 \\
\hline Positive Emotion (PE) & 0.924 & 10 \\
\hline Total (525) & 0.971 & 32 \\
\hline
\end{tabular}

with the content to be investigated. This study mainly uses structural validity to test the scale in the questionnaire. We choose the maximum variance rotation method in the testing. Generally speaking, if the KMO value is higher than 0.8 , the validity is good. If this value is between 0.7 and 0.8 , the validity is relatively good. If this value is between 0.6 and 0.7 , the validity is average. If this value is less than 0.6 , the validity is bad. By analyzing the validity of the questionnaire, we get the following results (See Table 3).

The validity was verified by KMO and Bartlett tests. From the above table, it can be seen that KMO value is $0.973, \mathrm{KMO}$ value is greater than 0.8 , and Bart's spherical test $(\mathrm{p}=0.000<0.05$ ) is passed, indicating that the validity of the research data is very good.

\section{Correlation Analysis and Regression Analysis}

Correlation analysis is a common method used to study the closeness statistics between variables, that is, to study the relationship between some quantitative data, such as whether there is a relationship and whether the relationship is close. ${ }^{56}$ Generally, the correlation coefficient is used to describe and analyze the degree of closeness. We analyze the related variables in this study by Pearson correlation (See Table 4).

It can be seen from the above table that the correlation analysis is used to study the correlation between trust and

Table 3 Samples Validity Analysis

\begin{tabular}{|l|c|c|}
\hline \multicolumn{2}{|l|}{$\begin{array}{l}\text { Kaiser-Meyer-Olkin Measure of Sampling } \\
\text { Sufficiency }\end{array}$} & $\mathbf{0 . 9 7 3}$ \\
\hline Sphericity test of Bartlett & Approximate chi-square & $18,476.420$ \\
& Df & 820 \\
& Sig. & 0.000 \\
\hline
\end{tabular}


Table 4 Pearson Correlation Between Variables $(\mathrm{N}=525)$

\begin{tabular}{|c|c|c|c|c|c|c|c|c|c|}
\hline & Mean & SD & Trust & RS & Satisfaction & PE & MI & DOC & WOCB \\
\hline Trust & 3.981 & 0.768 & I & & & & & & \\
\hline RS & 4.023 & 0.718 & $0.684^{* *}$ & I & & & & & \\
\hline Satisfaction & 3.922 & 0.791 & $0.637^{* *}$ & $0.779 * *$ & I & & & & \\
\hline PE & 4.025 & 0.688 & $0.698 * *$ & $0.728^{* *}$ & 0.776 ** & I & & & \\
\hline MI & 3.469 & 1.104 & $0.272 * *$ & $0.273^{* *}$ & $0.345^{* *}$ & $0.362 * *$ & I & & \\
\hline Time & 3.832 & 1.001 & $0.433^{* *}$ & $0.466 * *$ & $0.494^{* *}$ & $0.506 * *$ & $0.499 * *$ & I & \\
\hline WOCB & 3.969 & 0.817 & $0.662 * *$ & $0.782^{* *}$ & $0.828^{* *}$ & $0.755 * *$ & $0.321^{* *}$ & $0.476 * *$ & I \\
\hline
\end{tabular}

Note: Significance level $* * 00.01$.

Abbreviations: RS, relationship strength; PE, positive emotions; MI, monthly income; DOC, duration of co-tenancy; WOCB, the willingness of co-tenancy behavior.

relationship strength, satisfaction, positive emotion, monthly income, DOC and the Willingness of Co-tenancy Behavior. Pearson correlation coefficient is used to express the strength of the correlation. It shows that trust, relationship strength, satisfaction, positive emotion, monthly income, DOC and the Willingness of Co-tenancy Behavior are all significant, and the correlation coefficient values are $0.684,0.637,0.698$, $0.272,0.433$ and 0.662 , respectively, and the correlation coefficient values are all greater than 0 , which means trust and relationship strength $(\mathrm{r}=0.684, \mathrm{P}<0.01)$, satisfaction $(\mathrm{r}=0.637, \mathrm{P}<0.01)$, positive emotion $(\mathrm{r}=0.698, \mathrm{P}<0.01)$, monthly income $(\mathrm{r}=0.272, \mathrm{P}<0.01)$, DOC $(\mathrm{r}=0.433, \mathrm{P}<0.01)$ and the Willingness of Co-tenancy Behavior $(\mathrm{r}=0.662$, $\mathrm{P}<0.01)$ are positive correlation among them. So it can verify that Relationship Strength and trust for the group are significantly related to the Willingness of Co-tenancy Behavior, and it also can preliminarily verify hypothesis.

Regression analysis is a statistical analysis method based on correlation analysis, which can determine the quantitative relationship between two or more variables. ${ }^{57}$ We analyze the related variables through the analysis method of hierarchical regression, which is divided into several models to study the influence relationship between one variable (classified or quantitative) and another variable (quantitative), especially to judge the change of $\mathrm{R}$ squared after increasing the potential variable of relationship strength. The researchers used gender, education level, marital status and occupation as control variables, trust as independent variable, relationship strength as mediator variable and behavioral willingness as dependent variable, and conducted regression analysis on the questionnaire. The analysis results are shown in Table 5.

It can be seen from the above table that the hierarchical regression analysis involves 3 models. The independent variables in Model 1 are gender, education level, marital status, age and occupation. Model 2 adds trust on the basis of Model 1, Model 3 adds relationship strength on the basis of Model 2, and the dependent variable of the model is WOCB. When taking gender, education, age, marital status and occupation as independent variables and WOCB as dependent variables, the $\mathrm{R}$ square in the model is 0.012 , which means that the controlling variables such as gender, education, age, marital status and occupation can explain the $1.2 \%$ change of WOCB. The model failed the $F$-test $(\mathrm{F}=1.252, \mathrm{p}>0.05)$, that is, the controlling variables have no influence on behavior intention, so it is impossible to analyze the influence of independent variables on dependent variables in detail. For Model 2: After adding trust to Model 1, the change of $F$ is significant $(\mathrm{p}<0.05)$, which means that it has explanatory significance to the model after adding trust. In addition, the $\mathrm{R}$ square rises from 0.012 to 0.445 , which means that trust can produce $43.3 \%$ explanation for WOCB. Specifically, the regression coefficient of trust is 0.702 that is significant $(\mathrm{t}=20.122, \mathrm{p}=0.000<0.01)$. And it means that trust will have a significant positive impact on WOCB. This verifies $\mathrm{H} 1$ of this study again. For model 3: after adding relationship strength to model 2 , the change of $F$ is significant $(p<0.05)$, which means that the relationship strength has explanatory significance to the model. In addition, the $\mathrm{R}$ square rises from 0.445 to 0.648 , which means that Relationship Strength can produce $20.3 \%$ explanation for WOCB. Specifically, the regression coefficient of relationship strength is 0.705 , which is significant ( $t=17.251$, $\mathrm{p}=0.000<0.01$ ), it means that relationship strength will have a significant positive impact on WOCB.

In a word, through the above analysis, H1 is further verified: the trust effects have a positive impact on the 
Table 5 Results of Hierarchical Regression Analysis Between Variables $(n=525)$

\begin{tabular}{|c|c|c|c|c|c|c|c|c|c|c|c|c|}
\hline & \multicolumn{4}{|c|}{ Layer I } & \multicolumn{4}{|c|}{ Layer 2} & \multicolumn{4}{|c|}{ Layer 3} \\
\hline & b & se & $\mathbf{t}$ & $\mathbf{p}$ & b & se & $\mathbf{t}$ & $\mathbf{p}$ & b & se & $\mathbf{t}$ & $\mathbf{p}$ \\
\hline Constant & $4.003^{* *}$ & 0.209 & 19.159 & 0 & $1.219 * *$ & 0.209 & 5.83 & 0 & 0.277 & 0.175 & 1.58 & 0.115 \\
\hline Gender & -0.133 & 0.077 & -1.723 & 0.086 & -0.099 & 0.058 & -1.7 & 0.09 & -0.085 & 0.046 & -1.844 & 0.066 \\
\hline Education & 0.002 & 0.047 & 0.041 & 0.967 & -0.019 & 0.035 & -0.545 & 0.586 & -0.032 & 0.028 & -1.149 & 0.251 \\
\hline Age & 0.004 & 0.017 & 0.209 & 0.834 & 0.011 & 0.013 & 0.882 & 0.378 & -0.004 & 0.01 & -0.407 & 0.684 \\
\hline Ms & 0.154 & 0.088 & 1.763 & 0.079 & 0.112 & 0.066 & 1.704 & 0.089 & 0.099 & 0.052 & 1.883 & 0.06 \\
\hline Occupation & -0.024 & 0.029 & -0.806 & 0.421 & -0.016 & 0.022 & -0.717 & 0.473 & -0.016 & 0.018 & -0.932 & 0.352 \\
\hline Trust & & & & & $0.702^{* *}$ & 0.035 & 20.122 & 0 & $0.250 * *$ & 0.038 & 6.537 & 0 \\
\hline RS & & & & & & & & & $0.705^{* *}$ & 0.041 & $|7.25|$ & 0 \\
\hline$R^{2}$ & \multicolumn{4}{|c|}{0.012} & \multicolumn{4}{|c|}{0.445} & \multicolumn{4}{|c|}{0.648} \\
\hline $\mathrm{F}$ & \multicolumn{4}{|c|}{$F(5,5 \mid 9)=1.252, p=0.284$} & \multicolumn{4}{|c|}{$F(6,5 \mid 8)=69.338, p=0.000$} & \multicolumn{4}{|c|}{$F(7,5 \mid 7)=135.972, p=0.000$} \\
\hline
\end{tabular}

Notes: Dependent variable: the willingness of co-tenancy behavior (WOCB). Significance level $* * p<0.0$ I.

Abbreviations: MS, marital status; RS, relationship strength; PE, positive emotions; MI, monthly income; WOCB, the willingness of co-tenancy behavior; se, standard error.

Willingness of Co-tenancy Behavior(WOCB), that is the higher the degree of trust between the post-90's generation of drifter in Shenzhen, the stronger the Willingness of Cotenancy Behavior(WOCB). At the same time, it is found that Relationship Strength will have a significant positive impact on the Willingness of Co-tenancy Behavior, that is, the stronger Relationship Strength between them, the more the Willingness of Co-tenancy Behavior.

\section{Moderating Effect and Hypothesis Testing:} MI, DOC and Satisfaction

The research of moderator effect is mainly to study whether the independent variable trust has different influence on WOCB under different adjusting variables such as monthly income and DOC. To study the moderator effect, it is necessary to deal with the data. In this study, we mainly verify whether the variables in this study have a regulatory effect. Since the variables in this study are all quantitative data, we need to centralize the trust of independent variables, monthly income, DOC and satisfaction. The specific operation method is to measure the meaning of every variable first, and then subtract the mean of each variable to get the required value. Then, these values are multiplied to RS out the interactive items of each variable, and then the regression equation of WOCB to independent variable trust and moderator variable monthly income and DOC is made to obtain the measurement coefficient of each variable. Finally, the new measurement coefficient is obtained by analyzing the regression of WOCB to independent variable trust and moderator variable monthly income and DOC. The following are the data analysis results of the influence of the moderator variable monthly income and DOC on trust on WOCB, as shown in Table 6.

It can be seen from the above table that the regulation can be divided into three models. Model 1 includes independent variables (trust) and control variables such as gender, education, age, marital status and occupation; Model 2 adds adjusting variables (Monthly Income) on the basis of model 1 , and model 3 adds interactive terms (product terms of independent variables and adjusting variables) on the basis of model 2. For Model 1, the purpose is to study the influence of independent variable (trust) on dependent variable (WOCB) without interference of moderator variable (Monthly Income). It can be seen from the above table that the independent variable (trust) is significant $(\mathrm{t}=20.122, \mathrm{p}=0.000<0.05)$. It means that trust has a significant impact on WOCB. H1 is verified again: the trust effects have a positive impact on the Willingness of Co-tenancy Behavior (WOCB). It also can be seen from the above table that the interaction between trust and monthly income is significant ( $\mathrm{t}=$ $-2.754, p=0.006<0.05$ ). It means that the influence of trust on WOCB is significantly different when adjusting 
Table 6 Analysis of Regulatory Effect Results-Monthly Income (MI) ( $n=525)$

\begin{tabular}{|c|c|c|c|c|c|c|c|c|c|c|c|c|}
\hline & \multicolumn{4}{|c|}{ Model I } & \multicolumn{4}{|c|}{ Model 2} & \multicolumn{4}{|c|}{ Model 3} \\
\hline & b & se & $\mathbf{t}$ & $\mathbf{p}$ & b & se & $\mathbf{t}$ & $\mathbf{p}$ & b & se & $\mathbf{t}$ & $\mathbf{p}$ \\
\hline Constant & 4.012 & 0.157 & 25.606 & $0.000 * *$ & 4.052 & 0.154 & 26.233 & $0.000 * *$ & 4.076 & 0.154 & 26.512 & $0.000 * *$ \\
\hline Gender & -0.099 & 0.058 & -1.700 & 0.090 & -0.076 & 0.057 & -1.323 & 0.187 & -0.082 & 0.057 & -1.444 & 0.149 \\
\hline Education & -0.019 & 0.035 & -0.545 & 0.586 & -0.026 & 0.034 & -0.745 & 0.457 & -0.022 & 0.034 & -0.651 & 0.515 \\
\hline Age & 0.011 & 0.013 & 0.882 & 0.378 & 0.014 & 0.012 & $1.09 \mid$ & 0.276 & 0.013 & 0.012 & 1.059 & 0.290 \\
\hline MS & 0.112 & 0.066 & 1.704 & 0.089 & 0.063 & 0.066 & 0.957 & 0.339 & 0.055 & 0.065 & 0.847 & 0.398 \\
\hline Occupation & -0.016 & 0.022 & -0.717 & 0.473 & -0.018 & 0.022 & -0.811 & 0.418 & -0.014 & 0.022 & -0.666 & 0.506 \\
\hline Trust & 0.702 & 0.035 & 20.122 & $0.000^{* *}$ & 0.661 & 0.036 & 18.563 & $0.000 * *$ & $0.64 I$ & 0.036 & 17.737 & $0.000 * *$ \\
\hline MI & & & & & 0.107 & 0.025 & 4.239 & $0.000 * *$ & 0.134 & 0.027 & 4.968 & $0.000 * *$ \\
\hline Trust $*$ MI & & & & & & & & & -0.090 & 0.033 & -2.754 & $0.006 * *$ \\
\hline$R^{2}$ & \multicolumn{4}{|l|}{0.445} & \multicolumn{4}{|l|}{0.464} & \multicolumn{4}{|l|}{0.472} \\
\hline $\mathrm{F}$ & \multicolumn{4}{|c|}{$F(6,5 \mid 8)=69.338, p=0.000$} & \multicolumn{4}{|c|}{$F(7,5 \mid 7)=63.945, p=0.000$} & \multicolumn{4}{|c|}{$F(8,5 \mid 6)=57.613, p=0.000$} \\
\hline
\end{tabular}

Notes: Dependent variable: the willingness of co-tenancy behavior (WOCB). Significance level ** $\mathrm{p}<0.01$.

Abbreviations: MS, marital status; MI, monthly income; se, standard error.

the different levels of variable (monthly income) (see Figure 2).

As shown in the above figure, monthly income has a regulatory effect on trust and WOCB. When income is at a high level, $\mathrm{k}<1$, which means that when people's monthly income is higher, the relationship between trust and WOCB is weaker; when income is low, $\mathrm{k}>1$, that is, the lower people's income, the stronger the relationship between trust and WOCB. This proves H4 of this study: trust effect will affect Relationship Strength and Positive Emotion, and will further affect the Willingness of Cotenancy Behavior. However, this influence is negative when people are in high Monthly Income (MI) and negative when people are in low Monthly Income (MI).

For testing the regulatory effect, we analyze the regulatory effect of DOC (See Table 7).

It can be seen from the table that regulation is divided into three models. Model 1 includes independent variables (trust) and control variables such as gender, education, age, marital status and occupation, Model 2 adds moderator variables (DOC) on the basis of model 1, and model 3 adds interactive terms (product terms of independent variables and adjusting variables) on the basis of model 2 . The interaction between trust and DOC is not significant $(\mathrm{t}=-1.922$,

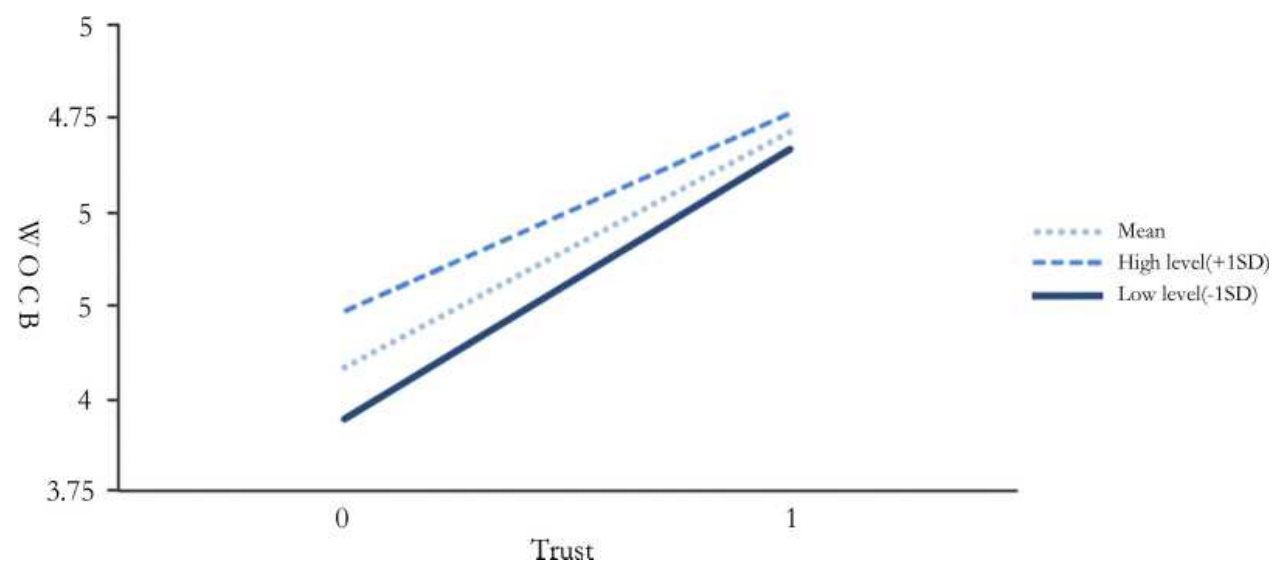

Figure 2 Simple slope diagram of the regulatory of monthly income. 
Table 7 Analysis of Regulatory Effect Results-DOC ( $=525)$

\begin{tabular}{|c|c|c|c|c|c|c|c|c|c|c|c|c|}
\hline & \multicolumn{4}{|c|}{ Model I } & \multicolumn{4}{|c|}{ Model 2} & \multicolumn{4}{|c|}{ Model 3} \\
\hline & b & se & $\mathbf{t}$ & $\mathbf{p}$ & b & se & $\mathbf{t}$ & $\mathbf{p}$ & b & se & $\mathbf{t}$ & $\mathbf{p}$ \\
\hline Constant & 4.012 & 0.157 & 25.606 & $0.000 * *$ & 3.931 & 0.151 & 25.949 & $0.000 * *$ & 3.962 & 0.152 & 26.073 & $0.000 * *$ \\
\hline Gender & -0.099 & 0.058 & -1.700 & 0.090 & -0.057 & 0.056 & -1.010 & 0.313 & -0.070 & 0.057 & -1.230 & 0.219 \\
\hline Education & -0.019 & 0.035 & -0.545 & 0.586 & -0.011 & 0.034 & -0.338 & 0.736 & -0.011 & 0.034 & -0.331 & $0.74 I$ \\
\hline Age & 0.011 & 0.013 & 0.882 & 0.378 & 0.015 & 0.012 & 1.193 & 0.233 & 0.015 & 0.012 & 1.263 & 0.207 \\
\hline MS & 0.112 & 0.066 & 1.704 & 0.089 & 0.079 & 0.064 & 1.246 & 0.213 & 0.082 & 0.063 & 1.297 & 0.195 \\
\hline Occupation & -0.016 & 0.022 & -0.717 & 0.473 & -0.004 & 0.021 & -0.192 & 0.848 & -0.005 & 0.021 & -0.222 & 0.824 \\
\hline Trust & 0.702 & 0.035 & 20.122 & $0.000 * *$ & 0.599 & 0.037 & 16.068 & $0.000 * *$ & 0.597 & 0.037 & 16.052 & $0.000 * *$ \\
\hline DOC & & & & & 0.185 & 0.029 & 6.396 & $0.000 * *$ & 0.182 & 0.029 & 6.292 & $0.000 * *$ \\
\hline Trust * DOC & & & & & & & & & -0.061 & 0.032 & -1.922 & 0.055 \\
\hline$R^{2}$ & \multicolumn{4}{|c|}{0.445} & \multicolumn{4}{|c|}{0.486} & \multicolumn{4}{|c|}{0.490} \\
\hline $\mathrm{F}$ & \multicolumn{4}{|c|}{$F(6,5 \mid 8)=69.338, p=0.000$} & \multicolumn{4}{|c|}{$F(7,5 \mid 7)=69.855, p=0.000$} & \multicolumn{4}{|c|}{$F(8,516)=61.903, p=0.000$} \\
\hline
\end{tabular}

Notes: Dependent variable: the willingness of co-tenancy behavior (WOCB). Significance level $* * p<0.01$.

Abbreviations: MS, marital status; DOC, duration of co-tenancy; se, standard error.

$\mathrm{p}=0.055>0.05$ ), and it can be seen from model 1 that when trust has an influence on WOCB, the influence range of the adjustment variable (DOC) is consistent at different levels. This shows that H5 of this study is not valid, that is, the DOC will not regulate the relationship between trust and WOCB.

In addition, we also analyze the regulatory effect of satisfaction (See Table 8.)

It can be seen from the above table that the regulation can be divided into three models, and Model 1 includes independent variables (trust). Model 2 adds regulatory variables (satisfaction) on the basis of model 1, and model 3 adds interactive terms (product terms of independent variables and regulatory variables) on the basis of model 2. For model 1, the purpose is to study the influence of independent variable (trust) on dependent variable (relationship strength) without the interference of adjustment variable (satisfaction). It can be seen from the above table that the independent variable (trust) is significant $(\mathrm{t}=21.451, \mathrm{p}=0.000<0.05)$. It means that trust has a significant impact on relationship strength. From the above table, it can be seen that the interaction between trust and satisfaction is not significant $(\mathrm{t}=-0.101$, $\mathrm{p}=0.920>0.05$ ), and from model 1 , when trust has an impact on the relationship strength, the adjustment

Table 8 Analysis of Regulatory Effect Results-Satisfaction ( $n=525)$

\begin{tabular}{|c|c|c|c|c|c|c|c|c|c|c|c|c|}
\hline & \multicolumn{4}{|c|}{ Model I } & \multicolumn{4}{|c|}{ Model 2} & \multicolumn{4}{|c|}{ Model 3} \\
\hline & b & se & $\mathbf{t}$ & $\mathbf{p}$ & b & se & $\mathbf{t}$ & $\mathbf{p}$ & b & se & $\mathbf{t}$ & $\mathbf{p}$ \\
\hline constant & 4.022 & 0.023 & 175.870 & $0.000 * *$ & 4.022 & 0.018 & 221.860 & $0.000 * *$ & 4.024 & 0.021 & 188.888 & $0.000 * *$ \\
\hline Trust & 0.640 & 0.030 & 21.451 & $0.000 * *$ & 0.296 & 0.031 & 9.648 & $0.000 * *$ & 0.296 & 0.031 & 9.634 & $0.000 * *$ \\
\hline Satisfaction & & & & & 0.524 & 0.030 & 17.615 & $0.000 * *$ & 0.524 & 0.030 & 17.569 & $0.000 * *$ \\
\hline Trust * Satisfaction & & & & & & & & & -0.003 & 0.029 & -0.101 & 0.920 \\
\hline$R^{2}$ & \multicolumn{4}{|c|}{0.468} & \multicolumn{4}{|c|}{0.666} & \multicolumn{4}{|c|}{0.666} \\
\hline $\mathrm{F}$ & \multicolumn{4}{|c|}{$F(1,523)=460.157, p=0.000$} & \multicolumn{4}{|c|}{$F(2,522)=521.289, p=0.000$} & \multicolumn{4}{|c|}{$F(3,52 I)=346.87 I, p=0.000$} \\
\hline
\end{tabular}

Notes: Dependent variable: relationship strength (RS). Significance level $* * p<0.01$. se, standard error. 
Table 9 Test of the Mediating Effect: PE and RS

\begin{tabular}{|l|l|l|l|l|c|c|}
\hline Mediation Path & Boot SE & Effect & $\mathbf{t}$ & $\mathbf{p}$ & 95\% BootLLCI-BootULCl & Conclusion \\
\hline Trust-PE-WOCB & 0.043 & 0.409 & 13.865 & 0.000 & {$[0.324,0.491]$} & Significant \\
\hline Trust-RS-WOCB & 0.063 & 0.254 & 4.003 & 0.0000 & {$[0.129,0.378]$} & Significant \\
\hline
\end{tabular}

Abbreviations: PE, positive emotion; RS, relationship strength; SE, standard error.

variable (satisfaction) has the same impact at different levels. Therefore, H6 does not hold.

\section{Intermediary Effects and Hypothesis Testing: RS and PE}

The main purpose of this part is to verify the mediating role of relationship strength and positive emotion in the relationship between trust and WOCB. First of all, trust is taken as an independent variable in this process, positive emotion as a mediator variable, monthly income as a moderator variable, and WOCB as a dependent variable. Bootstrap test is carried out through model 5 and model 7 in SPSS 25.0 plug-in process to verify the existence of mediation effect (See Table 9).

Through the mediation test method proposed by Ref. ${ }^{58}$, trust is taken as independent variable, relationship strength and positive emotion are taken as mediator variables, and WOCB is taken as dependent variable, and then use model 4 and model 7 to test. The confidence interval of $95 \%$ confidence interval of mediating effect (ind_eff) obtained by bootstrap method. Under $95 \%$ confidence interval and 3000 samples, it shows trust $(b=0.409, \mathrm{SE}=0.043,95 \%$ confidence interval: $[0.324,0.491])$ has a significant indirect effect on the WOCB, while trust $(b=0.254, \mathrm{SE}=0.063,95 \%$ confidence interval: $[0.129,0.378])$ has a significant indirect effect on the WOCB through Relationship Strength. This means that positive emotion and relationship strength play a mediator role in the study, so $\mathrm{H} 2$ and $\mathrm{H} 3$ are supported: Trust will affect Relationship Strength, and will further affect the Willingness of Co-tenancy Behavior. That is to say, the degree of trust among the post-90s who tend to share houses with others in Shenzhen will affect Relationship Strength, and then will affect people's willingness to co-tenant. And Trust will affect people's positive emotions, and will further affect the Willingness of Co-tenancy Behavior. That is to say, the degree of trust among the post-90s who tend to share houses with others in Shenzhen will affect people's positive emotions, and then will affect people's willingness to co-tenant. Based on this, we modify our research theoretical model (See Figure 3).

\section{Path Analysis \\ Confirmatory Factor Analysis}

The purpose of confirmatory factor analysis is to build a structural equation model better to verify the mediating role of relationship strength and positive emotion. Therefore, trust, relationship strength, positive emotion and WOCB are the main latent variables in SEM model, and their scale items are used as observation variables for verification. We count the number of factors and total (See Table 10).

It can be seen from the table that confirmatory factor analysis (CFA) is conducted for 4 factors and 27 analysis items. The effective sample size of this study is 525 , which is 10 times more than the number of analyzed items, so the sample size is moderate. And the result of the model is follow (See Table 11).

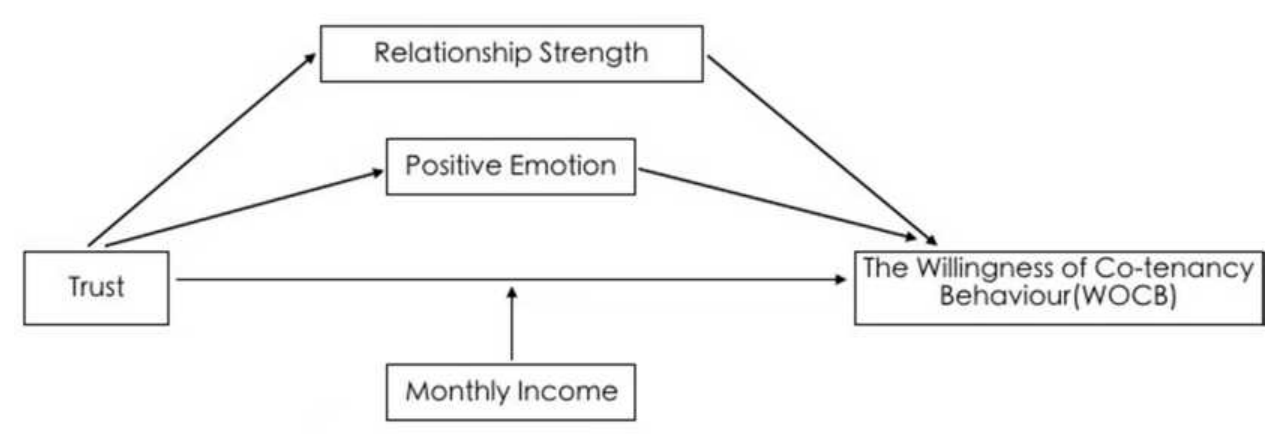

Figure 3 Research theoretical model (Final). 
Table 10 The Number of Factor

\begin{tabular}{|l|c|}
\hline Factor & Quantity \\
\hline Trust & 5 \\
\hline WOCB & 7 \\
\hline Relationship strength & 5 \\
\hline Positive emotion & 10 \\
\hline Total & 27 \\
\hline The number of Sample & 525 \\
\hline
\end{tabular}

Table I I AVE and CR Index Results in the Model a

\begin{tabular}{|l|l|c|}
\hline Factor & AVE & CR \\
\hline Trust & 0.634 & 0.896 \\
\hline The Willingness of Co-tenancy Behavior & 0.670 & 0.934 \\
\hline Relationship strength & 0.598 & 0.881 \\
\hline Positive emotion & 0.554 & 0.925 \\
\hline
\end{tabular}

AVE (Mean Variance Extraction) and CR (Combination Reliability) are mainly used to analyze convergence validity. Generally speaking, AVE is higher than 0.5 and $C R$ is higher than 0.7, which means that convergence validity is high. If AVE or $\mathrm{CR}$ is low, we can consider re-analyzing convergence validity after removing a certain factor. As can be seen from the above table, the confirmatory factor analysis (CFA) analysis was carried out on 4 factors and 27 analysis items, and it was found that the AVE corresponding to 4 factors was all higher than 0.5 , and the CR corresponding to 4 factors was all higher than 0.7 , which means that the result of this analysis has good convergence validity.

\section{Path Testing}

This part mainly tests the structure through Amos, and the goodness of fit of the structure model is tested by RMR, CFI, RMSR, AGFI, etc. Based on the model verified by SPSS, we repeatedly verify the mediating role of positive emotion and relationship strength in the model. Therefore, the structural model tests mainly the relationship between latent variable trust, positive emotion, relationship strength and WOCB. And the measurement relationship is mainly the relationship between different variables and observed variables (See Table 12.).

It can be seen from the above table that the value of the normalized path coefficient is $0.807>0$, and this path is significant $(\mathrm{z}=15.353, \mathrm{p}=0.000<0.01)$, so it can indicate that trust has a significant positive impact on the relationship strength. Relationship strength affects WOCB, the standardized path coefficient value is $0.587>0$, and this path is significant $(\mathrm{z}=12.006, \mathrm{p}=0.000<0.01)$. It is that relationship strength has a significant positive impact on WOCB. Trust affects positive emotion, the value of the standardized path coefficient is $0.797>0$, and this path is also significant $(\mathrm{z}=13.168, \mathrm{p}=0.000<0.01)$, which indicates that trust has a significant positive influence on positive emotion. Positive emotion affects behavior intention, the standardized path coefficient is $0.371>0$, and this path is significant $(\mathrm{z}=8.259, \mathrm{p}=0.000<0.01)$, which indicates that positive emotion has a significant positive influence on WOCB. To sum up, the hypothesis $\mathrm{H} 2$ and $\mathrm{H} 3$ are verified again.

To clear the relationship of different items, we do the measurement of expression relationship (See Table 13).

The measurement relation is shown in the table of measurement expression relation, and the measurement relation between latent variable and observed variable is shown in the scale of measurement relation. Generally speaking, the first item of measurement relation is the

Table 12 Summary Table of Model Regression Coefficient

\begin{tabular}{|l|l|c|c|c|c|c|c|}
\hline $\mathbf{X}$ & $\rightarrow$ & $\mathbf{Y}$ & Non-Standardized Path Coefficient & $\mathbf{s e}$ & $\mathbf{z}$ & $\mathbf{p}$ & Standardized Path Coefficient \\
\hline Trust & $\rightarrow$ & RS & 0.790 & 0.051 & 15.353 & 0.000 & 0.807 \\
\hline RS & $\rightarrow$ & WOCB & 0.574 & 0.048 & 12.006 & 0.000 & 0.587 \\
\hline Trust & $\rightarrow$ & PE & 0.784 & 0.060 & 13.168 & 0.000 & 0.797 \\
\hline PE & $\rightarrow$ & WOCB & 0.360 & 0.044 & 8.259 & 0.000 & 0.371 \\
\hline
\end{tabular}

Note: $\rightarrow$ indicates the path influence relationship.

Abbreviations: RS, relationship strength; PE, positive emotion; WOCB, the willingness of co-tenancy behavior; se, standard error. 
Table 13 The Result of Measurement Expression Relationship

\begin{tabular}{|c|c|c|c|c|c|c|c|}
\hline $\mathbf{x}$ & $\rightarrow$ & $\mathbf{Y}$ & NLF & se & $\mathbf{z}$ & $\mathbf{p}$ & SLF \\
\hline I usually have faith in roommates. & $\rightarrow$ & Trust & 1.000 & - & - & - & 0.769 \\
\hline I tend to rely on my roommates. & $\rightarrow$ & Trust & 1.024 & 0.057 & 17.943 & 0.000 & 0.751 \\
\hline I think human nature can be reliant. & $\rightarrow$ & Trust & 1.129 & 0.056 & 20.069 & 0.000 & 0.826 \\
\hline I usually trust others unless they give me a reason to distrust them. & $\rightarrow$ & Trust & 0.960 & 0.053 & 17.956 & 0.000 & 0.752 \\
\hline I think my roommates are generally reliable. & $\rightarrow$ & Trust & 1.106 & 0.054 & 20.662 & 0.000 & 0.846 \\
\hline I think it is convenient and feasible to choose co-tenancy. & $\rightarrow$ & WOCB & 1.000 & - & - & - & 0.771 \\
\hline Compared with living alone, I prefer to rent a houses with others. & $\rightarrow$ & WOCB & I.I44 & 0.059 & 19.382 & 0.000 & 0.787 \\
\hline Even if my funds permit, I prefer to continue co-tenancy. & $\rightarrow$ & WOCB & 1.266 & 0.062 & 20.571 & 0.000 & 0.826 \\
\hline I am willing to rent a houses with others. & $\rightarrow$ & WOCB & 1.209 & 0.058 & 20.865 & 0.000 & 0.835 \\
\hline I like the feeling of co-tenancy. & $\rightarrow$ & WOCB & 1.200 & 0.058 & 20.521 & 0.000 & 0.824 \\
\hline I am willing to recommend the co-tenancy lifestyle to others. & $\rightarrow$ & WOCB & 1.143 & 0.059 & 19.518 & 0.000 & 0.791 \\
\hline If my friend is considering co-tenancy, I will tell them the co-tenancy information. & $\rightarrow$ & WOCB & 1.225 & 0.058 & 21.184 & 0.000 & 0.845 \\
\hline I have similarities with my roommates. & $\rightarrow$ & RS & 1.000 & - & - & - & 0.769 \\
\hline I am familiar with my roommates. & $\rightarrow$ & RS & 0.966 & 0.055 & 17.599 & 0.000 & 0.745 \\
\hline When roommates are in trouble, I will try my best to help them out. & $\rightarrow$ & RS & 0.979 & 0.054 & 18.095 & 0.000 & 0.763 \\
\hline I will discuss personal topics with my roommates. & $\rightarrow$ & RS & 1.007 & 0.054 & 18.492 & 0.000 & 0.777 \\
\hline I am willing to make friends with my roommates. & $\rightarrow$ & RS & 1.035 & 0.053 & 19.481 & 0.000 & 0.812 \\
\hline I have endless energy. & $\rightarrow$ & PE & 1.000 & - & - & - & 0.639 \\
\hline I feel that I can do anything I want. & $\rightarrow$ & PE & 1.135 & 0.076 & 14.997 & 0.000 & 0.763 \\
\hline I like myself. & $\rightarrow$ & PE & 0.988 & 0.066 & 15.014 & 0.000 & 0.765 \\
\hline My thoughts are clear and creative. & $\rightarrow$ & PE & 0.905 & 0.060 & 15.116 & 0.000 & 0.771 \\
\hline I feel that people love me and trust me. & $\rightarrow$ & PE & 0.957 & 0.064 & 15.064 & 0.000 & 0.768 \\
\hline I feel close to the people around me. & $\rightarrow$ & PE & 0.946 & 0.063 & 14.950 & 0.000 & 0.760 \\
\hline My life is moving in the direction I want. & $\rightarrow$ & PE & 0.936 & 0.063 & 14.934 & 0.000 & 0.759 \\
\hline I often smile and laugh & $\rightarrow$ & PE & 0.937 & 0.063 & 14.850 & 0.000 & 0.754 \\
\hline I can handle anything that happens. & $\rightarrow$ & PE & 1.021 & 0.068 & 15.112 & 0.000 & 0.771 \\
\hline My future is bright. & $\rightarrow$ & PE & 0.914 & 0.063 & 14.535 & 0.000 & 0.734 \\
\hline
\end{tabular}

Note: $\rightarrow$ the measurement relationship.

Abbreviations: RS, relationship strength; PE, positive emotion; WOCB, the willingness of co-tenancy behavior; NLF, non-standardized load factor; SLF, standardized load factor; se, standard error.

control item, so there is no $\mathrm{SE}, \mathrm{z}$ and $\mathrm{p}$ value. If a certain path (ie, the measurement relationship) is not significant $(\mathrm{P}>0.05)$, it shows that there is a problem with the measurement relationship, and it can be considered to delete this path. It can be seen from the table that they are all less than 0.05 , so they are all significant.

The model fitting index is used to analyze the model fitting situation. Generally speaking, there are many model 
fitting indexes, and it is difficult to meet all the indexes. Therefore, people generally use several common indicators, including chi-square freedom ratio, GFI, RMSEA, RMR, CFI, NFI and NNFI. When the fitting index is not up to standard, it is suggested that the model relationship can be reset or adjusted by model MI correction. In this study, the result can be seen in the following table (See Table 14).

It is shown that these reference standards are all within the standard range of judgment, indicating that the fitting degree is good. It is that the model fitting is acceptable: $\mathrm{RMSEA}=0.071, \mathrm{SRMR}=0.058, \mathrm{CFI}=0.919, \mathrm{TLI}=0.911$.

\section{Research Conclusions and Discussion \\ Research Conclusions}

Overall, this study contributes to literature by establishing a mediation model, which helps people to understand these factors on the willing of co-tenancy behavior. Based on this, the research results of the study are as follows: the trust effects have a positive impact on the Willingness of Cotenancy Behavior(WOCB), that is the higher the degree of trust between the post-90's generation of drifter in Shenzhen, the stronger the Willingness of Co-tenancy Behavior(WOCB); Trust will also affect Relationship Strength, and will further affect the Willingness of Cotenancy Behavior. That is to say, the degree of trust among the post-90s who tend to share houses with others in

Table 14 Fitting Index of Structural Model

\begin{tabular}{|c|c|c|}
\hline Fitting Index & Model & Boundary \\
\hline \multicolumn{3}{|l|}{ Absolute fit measures } \\
\hline Chi-square $(\chi 2)$ & 1171.348 & - \\
\hline Degree of Freedom & 320 & - \\
\hline $\begin{array}{l}\text { Root mean square residual } \\
\text { (RMSEA) }\end{array}$ & $0.07 I^{* *}$ & $<0.10$ \\
\hline \multicolumn{3}{|l|}{ Incremental fit measures } \\
\hline Tucker-Lewis index (TLI) & $0.911 * *$ & $>0.90$ \\
\hline Normed fit index (NFI) & $0.892 * *$ & $\begin{array}{l}\text { The bigger the } \\
\text { better. }\end{array}$ \\
\hline SRMR & $0.058 * *$ & $<0.10$ \\
\hline Comparative fit index (CFI) & $0.919 * *$ & $>0.90$ \\
\hline \multicolumn{3}{|l|}{ Parsimonious fit measures } \\
\hline $\begin{array}{l}\text { Parsimonious normed fit index } \\
\text { (PNFI) }\end{array}$ & $0.813^{*}$ & $\begin{array}{l}\text { The bigger the } \\
\text { better. }\end{array}$ \\
\hline $\begin{array}{l}\text { Parsimonious goodness-of-fit } \\
\text { index (PGFI) }\end{array}$ & $0.706 *$ & $\begin{array}{l}\text { The bigger the } \\
\text { better. }\end{array}$ \\
\hline
\end{tabular}

Notes: Acceptability: * (fair), ${ }^{* *}$ (good).
Shenzhen will affect Relationship Strength, and then will affect people's willingness to co-tenant; Trust will affect people's positive emotions, and will further affect the Willingness of Co-tenancy Behavior. That is to say, the degree of trust among the post-90s who tend to share houses with others in Shenzhen will affect people's positive emotions, and then will affect people's willingness to co-tenant; Trust effect will affect Relationship Strength and Positive Emotion, and will further affect the Willingness of Cotenancy Behavior. However, this influence is negative when people are in high Monthly Income(MI) and negative when people are in low Monthly Income(MI). But in the study, it is invalid that trust effect will affect Relationship Strength, and will further affect the Willingness of Co-tenancy Behavior. However, this influence is positive when the duration of cotenancy required is shorter, and negative when the duration is shorter. And it is also not valid that trust effect will affect Relationship Strength; however, the influence is not positive when there is higher satisfaction and negative when there is not fewer satisfaction.

\section{Discussion}

The present studies have explored correlations between emotion and willingness ${ }^{59-63}$ And the relationship between relationship strength and willingness. ${ }^{64-66}$ At the same time, priority studies have consistently observed relationships among trust, positive emotion, relationship strength, satisfaction and the willingness. ${ }^{67-71}$ These scholars pay much more attention on different areas or social facts, but few studies have paid attention to the social phenomenon of joint rent in quantitative method.

From the analysis results above, the trust effects, relationship strength and positive emotion have a positive impact on the Willingness of Co-tenancy Behavior. Therefore, the authors believe that trust, relationship strength and positive emotion are key factors for people to rent houses with others. That is to say, the intensity of people's willingness to rent houses with others depends on the degree of trust in others, the relationship strength and positive emotion. When the post-90s drifters in Shenzhen do not believe others, they will tend to live alone rather than the new model of co-tenancy. We also suspect that a person with negative emotion far greater than positive emotion prefers to live alone, rather than living in the same place with his roommates.

Also, monthly income is an inevitable factor for the post-90s drifters in Shenzhen. Even if some post-90s said that joint co-tenancy is a new way of life, it has nothing to 
do with their monthly income. The authors that the group generally choose to rent houses with others to relieve the economic pressure due to economic and emotional factors. In most developed countries, shared housing is regarded as a short-term and cheap form of accommodation, and this form of accommodation often appears to meet the needs of single adults with limited income. ${ }^{72}$ In other words, the form of shared housing is usually aimed at young people, especially when housing costs are rising and social housing is relatively scarce. These young people are often in a period of rising career and are more constrained by the economy, so they choose to share the housing to relieve the economic pressure. It is because compared with the whole rent, co-tenancy can make the tenants share the fees from rent, water and electricity, which will be a huge financial buffer for young people who have just entered the society. But in the study, the regulating effect of the duration of co-tenancy required and satisfaction are invalid. In our analysis, the main reason is that when the post90s drifters in Shenzhen choose to rent houses with others, they will think less about how long they will stay. Generally, they put much more attention on their fledgling career. In addition, in recent times, security breaches from cyber attacks are on the rise, and they pose a significant threat to daily business operations in organizations. There is a strong case of data privacy and cybersecurity challenges that may arise when more users start staying at cotenant homes. So the proactive information security plays an essential role in enhancing the current level of cybersecurity.

\section{Research and Publication Ethics}

All subjects gave their informed consent for inclusion before they participated in the study. The study was conducted in accordance with the Declaration of Helsinki, and the protocol was approved by the Ethics Committee of Shenzhen University.

\section{Disclosure}

The authors declare no conflicts of interest in this work.

\section{References}

1. Doling J, Ronald R. Home ownership and asset-based welfare. J Housing Built Environ. 2010;25(2):165-173. doi:10.1007/s10901009-9177-6

2. Kawata N (2007) Single people in context of Japan's housing system. European network of housing research conference.Rotterdam, the Netherlands
3. Heath S, Davies K, Edwards G, Scicluna R. Shared Housing, Shared Lives: Everyday Experiences Across the Lifecourse. Routledge; 2017.

4. Kenyon E, Heath S. Choosing this life: narratives of choice amongst houses sharers. Housing Stud. 2001;16(5):619-638. doi:10.1080/ 02673030120080080

5. Kenyon E, Heath S. Choosing this life: narratives of choice amongst houses sharers. Housing Stud. 2001;16(5):619-635. doi:10.1080/ 02673030120080080

6. Goudge J, Gilson L. How can trust be investigated? Drawing lessons from past experience. Soc Sci Med. 2005;61(7):1439-1451. doi:10.1016/j.socscimed.2004.11.071

7. Larzelere RE, Huston TL. The dyadic trust scale: toward understanding interpersonal trust in close relationships. $J$ Marriage Fam. 1980;42(3):595-604. doi:10.2307/351903

8. Cummings LL, Bromiley P. The organizational trust inventory (OTI): development and validation. In: Kramer RM, Tyler TR, editors. Trust in Organizations: Frontiers of Theory and Research. London: Sage Publications; 1996.

9. Balliet D, Van Lange PA. Trust, conflict, and cooperation: a meta-analysis. Psychol Bull. 2013;139(5):1090-1112. doi:10.1037/ a0030939

10. Li T, Liu X, Pan J, Zhou G. The interactive effect of facial appearance and behavior statement on trust belief and trust behavior. Pers Individ Dif. 2017;117:60-65. doi:10.1016/j.paid.2017.05.038

11. Agneessens F, Wittek R. Social capital and employee well-being: disentangling intrapersonal and interpersonal selection and influence mechanisms. Revue Française de Sociologie. 2008;49(3):613-637. doi: $10.3917 / \mathrm{rfs} .493 .0613$

12. Rotenberg KJ. The conceptualization of interpersonal trust: a basis, domain, and target framework. In: Rotenberg KJ, editor. Interpersonal Trust During Childhood and Adolescence. Cambridge, MA: Cambridge University Press; 2010, pp. 8-27.

13. McAllister DH. Affect and cognition-base trust as foundations for interpersonal cooperation in organizations. Acad Manage J. 1995;(23):24-59.

14. Mechanic D, Meyer S. Concepts of trust among patients with serious illness. Soc Sci Med. 2000;51(5):657-668. doi:10.1016/S02779536(00)00014-9

15. Thom DH, Campbell B. Patient-physician trust: an exploratory study. J Fam Pract. 1997;44(2):169-176.

16. Thorne SE, Robinson CA. Guarded alliance: health care relationships in chronic illness. J Nurs Scholarship. 1989;21(3):153-157. doi:10.1111/j.1547-5069.1989.tb00122.x

17. Richins ML. Word of Mouth Communication as Negative Information. ACR North American Advances; 1984.

18. Zhu N, Lu HJ, Chang L. Trust as social investment: a life-history model of environmental effects on ingroup and outgroup trust. Pers Individ Dif. 2021;168:110303. doi:10.1016/j.paid.2020.110303

19. Gilson L. Trust and the development of health care as a social institution. Soc Sci Med. 2003;56:1453-1468. doi:10.1016/S02779536(02)00142-9

20. Davis. FD. Perceived usefulness, perceived ease of use, and user acceptance of information technology. MIS Quarterly. 1989;13 (3):319-340. doi:10.2307/249008

21. Breckler. SJ. Empirical validation of affect, Behavior, and cognition as distinct components of attitude. J Personality Soc Psychol. 1984;47(06):1191-1205. doi:10.1037/0022-3514.47.6.1191

22. Biswas B, Sengupta $P$, Chatterjee D. Examining the determinants of the count of customer reviews in peer-to-peer home-sharing platforms using clustering and count regression techniques. Decis Support Syst. 2020;135:113324. doi:10.1016/j.dss.2020.113324

23. Bansal HS, Voyer PA. Word-of-mouth processes within a services purchase decision context. J Serv Res. 2000;3(2):166-177. doi:10.1177/109467050032005

24. Smith DN. Trust Me, Would I Steer You Wrong? The Influence of Peer Recommendations Within Virtual Communities. University of Illinois at Chicago; 2002. 
25. Wang $\mathrm{T}$, Li Y. The influence of recommender characteristics on recommendation effect in virtual community. $J$ Business Econ. 2007;(11):50-55+80.

26. Lin X. An empirical study on the factors influencing the credibility of online word of mouth. Finance Trade Res. 2007;28:5.

27. Jidong B. Research on the Influence of Negative Internet Word of Mouth on Consumers' Behavior Intention. Shandong University; 2010.

28. Xiufang C. Research on the Influence of Online Word-Of-Mouth in Virtual Community on Consumers' Decision-Making Behavior. China university of mining and technology; 2011.

29. Shiota MN, Campos B, Keltner D, Hertenstein MJ. Positive emotion and the regulation of interpersonal relationships. Reg Emotion. 2004:68.

30. Dunn JR, Schweitzer ME. Feeling and believing: the influence of emotion on trust. J Pers Soc Psychol. 2005;88(5):736-748. doi:10.1037/0022-3514.88.5.736

31. Qiu L, Zheng X, Wang Y. Revision of PANAS. Appl Psychol. 2008;14(03):249-254+268.

32. Watson D, Wiese D, Vaidya J, et al. The two general activation systems of affect: structural findings, evolutionary considerations, and psychobiological evidence. J Personality Soc Psychol. 1999;76 (5):820-838. doi:10.1037/0022-3514.76.5.820

33. Drążkowski D, Kaczmarek LD, Kashdan TB. Gratitude pays: a weekly gratitude intervention influences monetary decisions, physiological responses, and emotional experiences during a trust-related social interaction. Pers Individ Dif. 2017;110:148-153. doi:10.1016/j. paid.2017.01.043

34. Wang Y, Xie G. The relationship between emotional intelligence, self-leadership and stress coping style of college students: the mediating effect of positive emotion and self-efficacy. Chin $J$ Clin Psychol. 2016;24(03):558-560+565.

35. Zhanjun X. Research on the relationship between residents' income and happiness in China. Sociol Res. 2011;25(01):196-219+245-246.

36. Hao Y. Residents' income and happiness: an empirical analysis based on housing adjustment effect. New Econ. 2020;(11):86-94.

37. Chao L, Zan Z. Research on the development path of "sharing economy" in China: taking online short rent as an example. Modern Manage Sci. 2014;(10):36-38.

38. Wang J. Research on development status, problems and countermeasures of long-term rental apartment industry. Housing Real Estate. 2016;33:237+240.

39. Wu S, Zhu J. The influence mechanism of online shopping experience quality on consumers' Behavior intention-the construction of conceptual model and hypothesis. Jianghuai Forum. 2015;03:48-53.

40. Junfeng C. Empirical Study on Influencing Factors of Household Satisfaction of Commercial Housing _ Taking Nanjing Urban Area as an Example [D]. Nanjing: Nanjing Forestry University; 2010.

41. Guiwen L, Yunsheng Z, Pengpeng X. Comprehensive evaluation of household satisfaction of public rental housing. Architectural Econ. 2013;(09):79-83.

42. Gefen (2002): The Relative Importance of Perceived Ease of Use in IS Adoption: AStudy of E-commerce Adoption

43. Lee MK, Turban E. A trust model for consumer internet shopping. Int $J$ Electronic Commerce. 2001;6(1):75-91. doi:10.1080/ 10864415.2001.11044227

44. Brown TJ, Barry TE, Dacin PA, Gunst RF. Spreading the word: investigating antecedents of consumers' positive word-of-mouth intentions and behaviors in a retailing context. J Acad Marketing Sci. 2005;33(2):123-138. doi:10.1177/0092070304268417

45. Sun T, Youn S, Wu G, Kuntaraporn M. Online word-of-mouth (or mouse): an exploration of its antecedents and consequences. J Comp Med Commun. 2006;11(4):1104-1127. doi:10.1111/j.10836101.2006.00310.x

46. Taylor S, Todd P. Assessing IT usage: the role of prior experience. MIS Quarterly. 1995;19(4):561-570. doi:10.2307/249633
47. Liping $\mathrm{C}$, Ziqiang $\mathrm{X}$, Liping $\mathrm{C}$. The relationship between happiness and social support. J Psychol. 2001;05:442-447.

48. Diener E, Emmons RA, Larsen RJ, Griffin S. The satisfaction with life scale. J Pers Assess. 1985;49(1):71-75. doi:10.1207/ s15327752jpa4901_13

49. Frenzen JK, David HL. Purchasing behavior in embedded markets. J Consumer Res. 1990;17(1):1 12. doi:10.1086/208532

50. Gilly MC, Graham JL, Wolfinbarger MF, Yale LJ. A dyadic study of interpersonal information search. J Acad Marketing Sci. 1998;26 (2):83-100. doi:10.1177/0092070398262001

51. Hair JF, Ringle CM, Sarstedt M. PLS-SEM: indeed a silver bullet. J Marketing Theory Pract. 2011;19(2):139-152. doi:10.2753/ MTP1069-6679190202

52. Kock N, Hadaya P. Minimum sample size estimation in PLS-SEM: the inverse square root and gamma-exponential methods. Inf Syst J. 2018;28(1):227-261. doi:10.1111/isj.12131

53. Yang C. Introduction to Research Methods of Mass Communication. 2nd ed. Beijing: Renmin University of China Press; 2015:91.

54. Zhang X, Yu X. The impact of perceived risk on consumers' crossplatform buying behavior. Front Psychol. 2020;11:2835. doi:10.3389/ fpsyg. 2020.592246

55. Li R. Empirical Research on the Influence of Cross-Border E-Commerce Credit Evaluation on Consumers' Online Purchase Decision. Beijing University of Posts and Telecommunications; 2018:26.

56. Preacher KJ, Hayes AF. Contemporary approaches to assessing mediation in communication research. In: Hayes AF, Slater MD, Synder LB, editors. The Sage Sourcebook of Advanced Data Analysis Methods for Communication Research. Thousand Oaks, CA: Sage; 2008:13-54.

57. Anderson CL, Agarwal R. The digitization of healthcare: boundary risks, emotion, and consumer willingness to disclose personal health information. Inf Syst Res. 2011;22(3):469-490. doi:10.1287/ isre. 1100.0335

58. Bonanno GA, Keltner D, Noll JG, et al. When the face reveals what words do not: facial expressions of emotion, smiling, and the willingness to disclose childhood sexual abuse. J Personality Soc Psychol. 2002;83(1):94. doi:10.1037/0022-3514.83.1.94

59. Burns KC, Isbell LM, Tyler JM. Suppressing emotions toward stereotyped targets: the impact on willingness to engage in contact. Soc Cogn. 2008;26(3):276-287. doi:10.1521/soco.2008.26.3.276

60. Graham SM, Huang JY, Clark MS, Helgeson VS. The positives of negative emotions: willingness to express negative emotions promotes relationships. Pers Soc Psychol Bull. 2008;34(3):394-406. doi: $10.1177 / 0146167207311281$

61. Von Culin KR, Hirsch JL, Clark MS. Willingness to express emotion depends upon perceiving partner care. Cogn Emot. 2018;32 (3):641-650. doi:10.1080/02699931.2017.1331906

62. Clark MS, Finkel EJ. Willingness to express emotion: the impact of relationship type, communal orientation, and their interaction. Pers Relatsh. 2005;12(2):169-180. doi:10.1111/j.1350-4126.2005.00109.x

63. Wiese J, Kelley PG, Cranor LF, Dabbish L, Hong JI, Zimmerman J (2011). Are you close with me? Are you nearby? Investigating social groups, closeness, and willingness to share. In Proceedings of the 13th international conference on Ubiquitous computing (pp. 197-206).

64. Setterstrom AJ, Pearson JM. Social influence and willingness to pay for massively multiplayer online games: an empirical examination of social identity theory. Commun Assoc Inf Syst. 2019;44(1):2. doi:10.17705/1CAIS.04402

65. Aboulnasr K, Tran GA. Is love really blind? The effect of emotional brand attachment on the perceived risk of really new products. $J$ Prod Brand Manage. 2019;29(1):81-96. doi:10.1108/JPBM-09-2018-2005

66. Evans MM, Frissen I, Choo CW. The strength of trust over ties: investigating the relationships between trustworthiness and tie-strength in effective knowledge sharing. Electronic J Knowledge Manage. 2019;17:1 
67. Matsui T, Yamada S. Designing trustworthy product recommendation virtual agents operating positive emotion and having copious amount of knowledge. Front Psychol. 2019;10:675. doi:10.3389/ fpsyg.2019.00675

68. Mangus SM, Bock DE, Jones E, Folse JAG. Examining the effects of mutual information sharing and relationship empathy: a social penetration theory perspective. J Bus Res. 2020;109:375-384. doi:10.1016/j.jbusres.2019.12.019

69. Song H, Wang J, Han H. Effect of image, satisfaction, trust, love, and respect on loyalty formation for name-brand coffee shops. Int J Hosp Manage. 2019;79:50-59. doi:10.1016/j.ijhm.2018.12.011
70. Druta O, Ronald R. Living alone together in Tokyo share houses. Soc Cultural Geography. 2020;1-18. doi:10.1080/14649365.2 020.1744704

71. Biswas B, Mukhopadhyay A. G-RAM framework for software risk assessment and mitigation strategies in organisations. J Enterprise Inf Manage. 2018;31(2):276-299. doi:10.1108/JEIM-05-2017-0069

72. Kumar S, Biswas B, Bhatia MS, Dora M. Antecedents for enhanced level of cyber-security in organisations. $J$ Enterprise Inf Manage. 2020. doi:10.1108/JEIM-06-2020-0240

\section{Publish your work in this journal}

Psychology Research and Behavior Management is an international, peer-reviewed, open access journal focusing on the science of psychology and its application in behavior management to develop improved outcomes in the clinical, educational, sports and business arenas. Specific topics covered in the journal include: Neuroscience, memory and decision making; Behavior modification and management; Clinical applications; Business and sports performance management; Social and developmental studies; Animal studies. The manuscript management system is completely online and includes a very quick and fair peer-review system, which is all easy to use. Visit http://www. dovepress.com/testimonials.php to read real quotes from published authors. 